\title{
RETHINKING CORPORATE SOCIAL RESPONSIBILITY: FOUNDATIONS FOR A VIABLE RECONCEPTUALIZATION
}

DOI: 10.17261/Pressacademia.2017.374

RJBM-V.4-ISS.1-2017(9)-p.90-95

\section{Veli Denizhan Kalkan}

Istanbul Medeniyet University, Department of Management, North Campus, Uskudar,34720 Istanbul,Turkey. denizhan.kalkan@medeniyet.edu.tr

To cite this document

Kalkan, V. D., (2017). Rethinking corporate social responsibility: foundations for a viable reconceptualization. Research Journal of Business and Management (RJBM), V.4, Iss.1, p.90-95.

Permemant link to this document: http://doi.org/10.17261/Pressacademia.2017.374

Copyright: Published by PressAcademia and limited licenced re-use rights only.

\begin{abstract}
Purpose- Corporate social responsibility has long been an issue of debate among practitioners and researchers. Recent global developments and problems in practice have led to a need for rethinking on the concept of social responsibility. This paper aims to discuss some important aspects of this need and identify issues subject to further research.

Methodology- Based on a holistic literature review, basic definitions and principles of corporate social responsibility have been investigated in the light of actual challenges faced.

Findings- Thoughts and suggestions about integrating the concept of the right to life into the processes of corporate social responsibility have been provided. It has been asserted that corporate social responsibility should be studied with organizational learning processes, micro-management, and social loafing concepts and issues. A discussion over various topics included in the process of rethinking and restructuring corporate social responsibility is offered, and ideas and suggestions potentially useful in the process have been put forward. Conclusion- The discussion provided has revealed a number of concerns and issues relevant to a viable reconceptualization of corporate social responsibility.
\end{abstract}

Keywords: Corporate social responsibility (CSR), social loafing, micro-management, organizational learning, management thought JEL Codes: M14, M16, Z18

\section{KURUMSAL SOSYAL SORUMLULUĞU YENIDEN DÜŞÜNMEK: UYGULANABILLIR BIRR YENIDEN KAVRAMSALLAŞTIRMANIN TEMELLERI}

\section{ÖZET}

Amaç- Kurumsal sosyal sorumluluk, uzun zamandan beri işletme yöneticileri ve akademisyenlerin temel tartışma başlıklarından biridir. Son dönemdeki çeşitli küresel gelişmeler ve uygulama sorunları, sosyal sorumluluk kavramı üzerine yeniden düşünülmesini zorunlu kılmaktadır. $\mathrm{Bu}$ çalışmada, kurumsal sosyal sorumluluğun yeniden kavramsallaştırılmasına katkıda bulunulması ve ileri araştırmalar için yararlı olabilecek spesifik başlıkların belirlenmesi amaçlanmaktadır.

Yöntem- Bütünsel bir literatür incelemesine dayalı olarak; kurumsal sosyal sorumluluğa ilişkin temel kavram ve ilkeler, güncel meydan okumalar ışı̆̆ında gözden geçirilmektedir.

Bulgular- Yaşam hakkı kavramının kurumsal sosyal sorumluluk süreçlerine entegre edilmesine ilişkin düşünce ve öneriler sergilenmektedir. Kurumsal sosyal sorumluluğun örgütsel öğrenme süreçleri, mikro yönetim ve sosyal aylaklık kavram ve konuları ile birlikte değerlendirilmesinin gerektiği öne sürülmektedir. Ayrıca, kurumsal sosyal sorumluluğun yeniden kurgulanması ve yapılandırılması sürecindeki çeşitli başlıkları içeren bir tartışma yürütülmekte ve süreçte yarar sağlayabilecek çeşitli düşünce ve öneriler ifade edilmektedir. Sonuç- Yürütülen tartışma, kurumsal sosyal sorumluluğun sağlıklı bir biçimde yeniden kavramsallaştırılmasında yararlı olabilecek bir dizi başlık ve yaklaşımı ortaya çıkarmıştır.

Anahtar Kelimeler: Kurumsal sosyal sorumluk (KSS), sosyal aylaklık, mikro yönetim, örgütsel öğrenme, yönetim düşüncesi JEL Kodları: M14, M16, Z18 
"insan için oksijen ne ise işletme için de kâr odur. Yeterli miktarda sahip olamadığınızda, oyunun dışında kalırsınız. Ancak hayatınızın nefes almaktan ibaret olduğunu düşünüyorsanız, gerçekten bir şeyleri kaçırıyorsunuz demektir."11

\section{GiRiş}

Kurumsal sosyal sorumluluk (KSS), son on yıllarda, iş dünyasının ve akademinin en önemli tartışma başlıklarından biri ve işletme okullarının müfredatlarında giderek daha fazla yer kaplayan bir konu haline gelmiştir (Bessant and Tidd, 2015; Thompson et al., 2016). Bu kavram, uzunca bir süredir işletmelerin çeşitli yasal gereklilikleri karşılamalarının çok ötesinde bir içeriğe işaret etmekte (Bénabou and Tirole, 2009); sürdürülebilirlik kavramı ile birlikte ele alınarak, daha yaşanabilir bir dünyanın anahtarlarından biri olarak değerlendirilmektedir (Gil Estallo et al., 2007; Evans et al., 2013). Öte yandan; kavramın giderek yaygınlaşması, kurumsal sosyal sorumluluğun uygulamada içeriğini yitirerek yönetim modalarından birine dönüşmesi riskini de beraberinde getirmektedir (Frankental, 2001). Özellikle pratikte yaşanan çeşitli -ve çoğunluğu olumsuz içerikli ya da en azından çağrışımlı- durumlardan kaynaklanan meydan okumalar, kavram üzerine yeniden düşünmeyi zorunlu kılmaktadır (Quelch and Jocz, 2009; Sanford, 2011). Bu çalışmada, kurumsal sosyal sorumluluk kavramının yönetim düşüncesi tarihindeki evrimi göz önünde bulundurularak, kavramın günümüzde karşı karşıya olduğu başlıca meydan okumalar tartışılacak ve kavramın tanım ve içeriğinde gerçekleştirilmesi yararlı olabilecek revizyon önerileri ele alınacaktır. Bu revizyon önerileri "temel tanım ve ilkeler", "kurumsal sosyal sorumlulukla ilişkilendirilmesi gereken öncelikli konular" ve "KSS'nin kurgulanışı ve yapılandırılmasına dair genel öneriler" üzerine odaklanacaktır. Literatür analizine dayalı kavramsal bir inceleme yoluyla ilgili konular ele alınıp tartışıldıktan sonra, ileri araştırmalar için öneriler ve yöneticiler için çıkarımlar ortaya koyulacaktır.

\section{LITERATÜR INCELEMESI: TEORI VE UYGULAMADA KURUMSAL SOSYAL SORUMLULUK}

Sosyal sorumluluk kavramının köklerine dair izler oldukça eskilerde, çağdaş işletmeciliğin ortaya çıkmasından önceki asırların ticari yaşamında bulunmaktadır (Walton, 1968; Luthans and Hodgetts, 1972). Yöneticilerin ve örgütlerin sosyal sorumluluklarına ilişkin söylemler ise, 1950'lerle birlikte belirgin bir biçimde dillendirilmeye başlanmıştır (Abrams, 1951; Bowen, 1953). Sonrasında, kurumsal sosyal sorumluluğun işletmecilik gündemindeki sistematik kavramsallaştııımasının aleyhinde kayda değer görüşler (Hayek; 1967; Friedman, 1970; Henderson, 2001) de açığa çıkmış olmakla birlikte; KSS'ye yönelik ilgi ve kabul düzeyi giderek yükselmiştir (Kusunoki, 2016). Konuya ilişkin farklı değerlendirme ve sınıflandırmalar ise erken dönemlerden itibaren su yüzüne çıkmış, değişik algı ve bakış açıları on yıllar boyunca hiç eksik olmamıştır (Klonoski, 1991; Garriga and Melé, 2004). Evrensel ölçekte kabul gören bir KSS tanımı üretilememiştir (Freeman and Hasnaoui, 2011; Orlitzky et al., 2011). Bununla birlikte; KSS'nin işletmenin paydaşları, içinde yaşam bulduğu çevre ve bir bütün olarak toplum karşısındaki sorumluluklarını ifade ettiği düşüncesi çoğunlukla benimsenmektedir (Blowfield and Murray, 2008; Nalband and AlAmri, 2013; Moon, 2014; Hino and Zennyo, 2017). İlk hali ile 1979'da formüle edilen ve sonrasında geliştirilerek yaygın kabul gören sosyal sorumluluk piramidi; aşağıdan yukarıya doğru ekonomik, hukuki, etik ve gönüllü (hayırsever) sosyal sorumluluk türlerinden oluşan bir bütünlüğü içermektedir (Carroll, 1979; Carroll, 1991). Anlaşılması kolay olan ve meseleleri toparlayıcı bir işlev gören bu çerçeve yaygın kabul görmüştür. ${ }^{2}$ Literatürde, şirketlerin, eylemleriyle açığa çıkan ekolojik problemlerin çözülmesinden sorumlu oldukları da ifade edilmiştir (Shrivastava, 1994). 2000'lerle birlikte daha kapsamlı, gerçekçi ve sürdürülebilir sosyal sorumluluk yaklaşımları üretilmeye başlanmıştır (Carroll and Shabana, 2010). Kurumsal sosyal sorumluluk, firmanın toplum üzerindeki zararlı etkilerini minimize ve uzun vadeli olumlu/faydalı etkilerini maksimize etmeye yönelik bir bağılığı olarak değerlendirilmiştir (Mohr et al., 2001). Günümüz iş dünyasında, KSS'nin bir trend olmaktan çıkarak norm olma yoluna girdiği açıkça görülmektedir. Firma stratejisinin bütünleşik bir parçası ve toplumsal meşruiyet sağlayan bir yapı olan KSS'nin sürdürülebilir olması için, vizyon ve misyonla bütünleşik bir biçimde kurgulanması gerektiği ifade edilmektedir (Randel, 2002; Quelch and Jocz, 2009).

Teorik tartışmaların, kurumsal sosyal sorumluluk kavramının daha iyi anlaşılmasına yönelik katkı sağladıkları görülmektedir. Sosyal sorumluluk anlayışının uygulamadaki şekillenişi ise oldukça problemlidir. Kuramsal tartışma düzleminde açığa çıkan çeşitli ilerlemelerin pratik iş uygulamaları düzeyinde içselleştirilebildiklerini öne sürmek güçtür. KSS'nin, yöneticiler tarafından, fiiliyatta çevresel ve sosyal sorumluklardan ziyade özel çıkarlara hizmet edecek biçimde yapılandırıldığı eleștirisi uzunca bir süredir gündemdedir (Welford, 1997). İşletmeler dünyasında sosyal sorumluluk söyleminin, çoğunlukla şirket karşıtı aktivist grupların baskılarına karşı üretilen propaganda ağırlıkı bir söylem olarak ele alındığı ve dolayısıyla KSS'nin bir propaganda aracı olarak kurgulandığı öne sürülmektedir (Burke, 2005; D’Amato et al., 2009; Fleming and Jones, 2013). Geçtiğimiz yıllarda, KSS'nin uygulama alanındaki çeşitli sınırlılıkları, özellikle küresel yoksullukla mücadele ve sürdürülebilir kalkınma alanlarına destek sunma noktasındaki zafiyetleri belirginleşmiştir (Banerjee, 2007). Firmaların KSS pratikleri ile benimsediklerini öne sürdükleri KSS standartları arasında ciddi çelişkiler bulunduğu ve bunların çalışan haklarını olumsuz yönde etkiledikleri ifade edilmiştir (Wagner et al., 2009; Compa, 2015). KSS bağlamındaki başarısızlıklar ve sorumsuz iş uygulamaları -can kayıpları dahil- çeşitli olumsuz/yıkıcı sonuçlara yol açmışlardır (Kanji and Chopra, 2010; Ofodile et al., 2012; Isaksson et al., 2014). Şirket skandalları ve benzeri sonuçlar iş liderlerine duyulan güveni azaltmıştır (Wagner et al., 2009; Evans et al., 2013). Sosyal sorumluluk piramidindeki son kademede yer alan gönüllü sosyal sorumluluk kapsamında değerlendirilebilecek olan hayırseverlik projeleri, işletmelerin bir kısmı tarafından sosyal sorumluluk meselesinin özü gibi ele alınarak ön plana çıkarılmıştır (Ersöz, 2007; Kağnıcıoğlu, 2007). Temellerden feragat edilerek, görünür olan ve reklamı yapılabilene odaklanma söz konusu olmuştur. Reklam yapmanın gerçekleştirmekten daha önemli hale geldiği bir KSS kavrayışı ve uygulamasının örnekleri açığa çıkmıştır (Baraz, 2011). Bu durum, -en iyimser değerlendirme ile- sosyal sorumluluğu süreli projelere hapsetmiştir. Süreli projelere yönelik aşırı ilgi ise, sürekli ilişkileri ve yaşamsal düzenlemeleri ihmal eden bir anlayışı beslemiştir. Sonuçta ortaya çıkan; temel gereksinimleri sistematik olarak görmezden gelen işletme uygulamalarının ve hatta yaşam hakkını dahi ihlal eden iş örgütlenmesi modellerinin varlık bulabilmeleri olmuştur (Malan, 2005; Isaksson et al., 2014; TBB, 2014; Yalman ve Çelik, 2016).

Geldiğimiz noktada, hem ilgili yöneticiler hem de araştırmacılar sosyal sorumluluk kavram ve uygulamalarını gözden geçirmek durumundadırlar. Örgütler KSS'yi bir propaganda enstrümanı olarak ele almaktan vazgeçmeli; insanlığın 21. yüzyılda eriştiği standartlarla uyumlu bir sosyal sorumluluk perspektifi üretme ve bunu pratiğe aktarma kaygısılla hareket etmelidirler. Akademisyenler ve yönetim düşünürleri ise, sosyal sorumluluğun içerik ve temel ilkelerini yeniden belirlemeye odaklanmalıdırlar. Bunun için öncelikle sosyal

\footnotetext{
${ }^{1}$ Peter Senge tarafından Peter Drucker'a atfedilen bir söz (Liu, 2010).

${ }^{2}$ Bununla birlikte, çerçevenin mimarının da eş-yazar olarak yer aldığı daha sonraki bir çalışmada, gönüllü sosyal sorumluluğun KSS'nin ana kategorilerden biri olarak değil, ekonomik ve/veya ahlaki sosyal sorumluluk alanlarının bütünleşik bir parçası olarak resmedilmiş olduğu belirtilmelidir (Schwartz and Carroll, 2003).
} 
sorumluluktan ne anlaşıldığını ifade eden söylemler, bir başka deyişle sosyal sorumluluk tanım ve ilkeleri üzerinde durulmalıdır. Yalnızca sağlıklı tanımlar üretme noktasında katkıda bulunmak yeterli olmayacağından, kurumsal sosyal sorumlulukla ilişkilendirilmesi öncelikli önem arz eden temel konular üzerinde de düşünülmelidir. Ayrıca sosyal sorumluluğun genel algılanışı, kurgulanışı ve yapılandırılması konusunda da revizyon önerileri üretilmelidir.

\section{TARTIŞMA: KSS TANIM VE ILKELERI, İLiŞKILI KAVRAMLAR VE KSS'NIN YAPILANDIRILMASI}

\subsection{Tanım ve ilkeler}

Sosyal sorumluluğun işletmeler düzeyinde sağlıklı bir biçimde formüle edilmesi, sınırlandırılmamış kâr hırsının yıkıcı etkilerini azaltma noktasında katkı sağlayabilecek bir girişimdir. Söz konusu formülasyon, KSS tanımlarındaki içeriğin olgular ve zamanın ihtiyaçları ile uyumu ölçüsünde başarılı olabilecektir. Günümüzde kurumsal sosyal sorumluluk tanımlarındaki mevcut içeriğe yönelik temel meydan okuma, pratik iş uygulamalarında açığa çıkmaktadır: Yaşam hakkını dahi ihlal edebilecek açıklara sahip iş örgütlenmelerinin varlığı (Yalman ve Çelik, 2016) sosyal sorumluluk tanım ve prensiplerinin güncellenmelerini zorunlu kılmaktadır. Ayrıca, üretimin yapısında ve iş organizasyonunda büyük değişikliklerin yaşandığı bir dönemde, KSS gündeminin çalışanların temel hakları ve sağlıklarına ilişkin konuları içermesi oldukça önemlidir (ILO, 2009). Dolayısıyla; tıbbın birinci ilkesi olarak ifade edilen ve Hippocrates'e atfedilen meşhur söz, yani "Primum non nocere (Önce zarar verme)!" prensibi, sosyal sorumluluk bağlamında da ön plana çıkarılmalıdır. "Zarar vermemek", öncelikle "yaşam hakkını korumak" olarak uyarlanmalı ve gündemleştirilmelidir. Genel olarak zarar vermemenin ve daha sonrasında fayda üretmenin nasıl gerçekleştirilebileceği ise somutlaştırılmalıdır. Bunun için, sektör bazında uyulması zorunlu temel KSS bildirgeleri oluşturulmalı ve bu bildirgeler prensiplerin denk düştükleri uygulamaları içerecek şekilde kurgulanmalıdır. Öncelikle, yaşam hakkının korunmasına ilişkin yapılması gerekenlerin her bir sektörde denk düştüğü uygulamalar açıklığa kavuşturulmalıdır. Madencilik sektöründe yaşam odasının zorunlu kılınması, radyasyonla ilişkili iş alanlarında ise yeterli sürelerde radyasyon izninin koşulsuz tanınması bu bağlamda örnek olarak zikredilebilirler. Sektör bazlı müşahhas uygulama karşılıkları belirlenmemiş prensiplerin, yaşama geçirilme şanslarının olmayacağı göz önünde bulundurulmalıdır.

\section{2. İlişkilendirilmesi Gereken Kavramlar/Konular}

Sosyal sorumluluk yalıtımış bir biçimde değil, kendisiyle ilişkilendirilmesi öncelik arz eden kavram ve konularla birlikte ele alınmalıdır. KSS şimdiye kadar genellikle performans, yönetişim, sürdürülebilirlik, şirket ünü, rekabetçilik, örgütsel bağ|ılık, liderlik ve etik gibi kavramlarla birlikte çalışılmıştır (Fukukawa et al., 2007; Damato et al., 2009; Turker, 2009). Bu çalışma ise, sosyal sorumlulukla birlikte ele alınmalarının öncelikli ve özel önem arz ettiği düşünülen üç kavramı/konuyu gündemleştirmektedir. Birinci kavram, örgütsel öğrenmedir. Örgütsel öğrenme, enformasyon işleme yoluyla örgütün potansiyel davranış alanının genişletilmesini ifade etmektedir (Huber 1991). Örgütsel öğrenme süreci, -KSS süreçlerinde de ihtiyaç duyulacak olan- enformasyon ve bilginin sürekli geliştirilmesini amaçlayan faaliyetleri içermektedir (Dixon, 1992). Öğrenme, örgütün seçeneklerini artırarak ihtiyaç duyduğu hareket alanını kendisine sunacaktır. Öğrenme süreçlerinin sürekliliğini sağlayamamış kuruluşların, sosyal sorumluluklarını yerine getirmelerini beklemek gerçekçi değildir. Bir diğer kavram olan sosyal aylaklık (kaytarma), bireylerin grup süreçleri içinde yer alan çeşitli aktivitelerde fiziksel veya zihinsel emeklerini -bireysel çalışmadakine nazaran- daha fazla geri çekme eğilimlerini ifade etmektedir (Liden et al., 2004). Sosyal aylaklık KSS performansı açısından sıkıntı oluşturabileceği gibi, KSS ile ilişkili çabalar da sosyal aylaklığı zayıflatıcı sonuçlara neden olabilmektedirler (Flammer and Luo, 2017). Üçüncü kavram ise mikro yönetimdir. Detayları ve kontrol gerekliliğini -örgütün gelişimini engelleme pahasına- öne çıkaran bir örgütsel patolojiyi ifade eden mikro yönetim, gözetimci yaklaşımıyla firmayı stratejik bakış açısından uzaklaştırabilmektedir (Wright, 1999; White, 2010). Bundan dolayı, sosyal sorumluluk anlayışının problemli bir biçimde şekillenmesinde rol oynayabilecek bir dizi etken arasında yer alma olasılığı bulunmaktadır. Etik ve işlevsel yönetim için, sorumlulukların belirliliği önemlidir. Mikro yönetim ise, pek çok yönetim kademesini işlevsizleştirerek etik ve işlevsel yönetimin zeminini ortadan kaldırabilmektedir.

Şekil 1: Kurumsal Sosyal Sorumlulukla iliş̧kilendirilmesi Önerilen Kavramlar/Konular

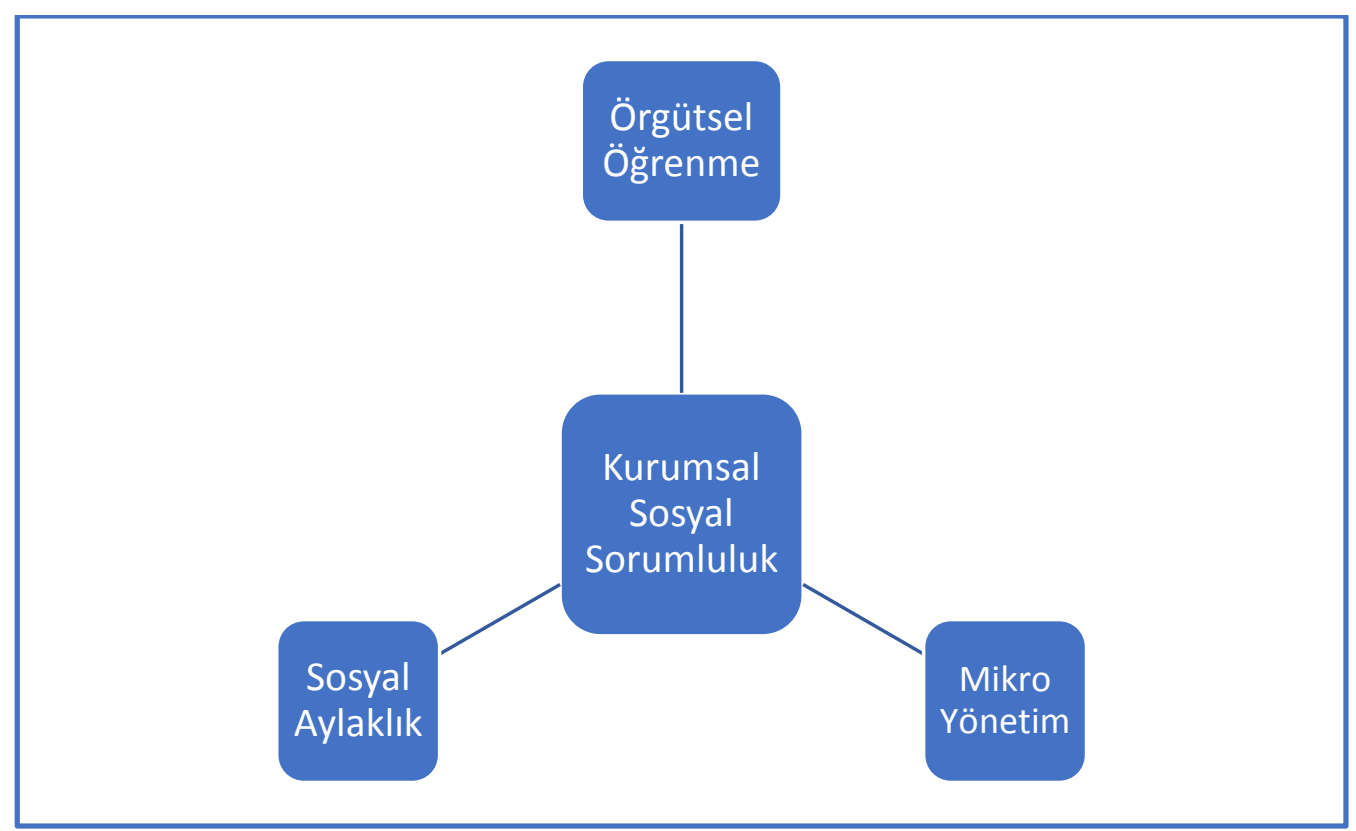

Şekil 1'de görülen üç temel kavramın/konunun KSS ile ilişkiler bağlamında ele alınarak değerlendirilmeleri, KSS ve çıktılarının daha gerçekçi bir düzeyde anlaşılmalarına zemin hazırlayacaktır. Değerlendirmelerden elde edilecek bulgular, örgütlerin sistematik KSS uygulamaları 
konusundaki hazırlıklılık düzeylerinin göstergeleri olarak da düşünülebilirler. Sosyal aylaklık, öğrenme süreçleri ve mikro yönetimin örgütteki mevcut durumları; KSS için işaretler ve öngörü fırsatları oluşturacak, gerekli düzeltme ve müdahalelerin erken yapılması için imkân sunacaklardır.

\subsection{KSS'nin Yapılandırılmasına ilişkin Genel Öneriler}

Literatürde, KSS'nin toplumsal yönlerinin ihmal edildiği ifade edilmektedir (Brammer et al., 2012). Mevcut yapısı ve algılanışı itibarı ile toplumdan ziyade şirketler için yararlı olan KSS'nin potansiyeli ve sürdürülebilir ekonomi noktasındaki katkıları da sınırlıdır (Banerjee, 2007, p. 146-147). Dolayısıyla, KSS üzerine yeniden düşünürken ve sosyal sorumluluk uygulamalarını tasarlarken, kavramın nihayetinde bütün toplumu ilgilendirdiği gerçeği gözden kaçııımamalıdır. Toplumun bütün kesimlerini temsil eden ortak aklın olur verdiği bir sosyal sorumluluk anlayışının iş dünyasında hâkim olması yararlı olacaktır. Bu, gerçekçilik ve sürdürülebilirlik açılarından önemlidir. Gerçekçi ve sürdürülebilir bir temelde kurgulanmamış sosyal sorumluluk uygulamaları arzulanan sonuçlara ulaştıramayacaktır. Sosyal sorumluluk anlayışının bilimsel bulgular ve güncel meydan okumalar ışığında yeniden ele alınması, işletmelerde sürdürülebilir yönetim geliştirmeye destek sağlayacağı gibi, ayrışma dinamiklerinin iyice görünür hale geldikleri ortamlarda birleştirici dinamiklerin yeniden güç kazanmalarına da katkı sunacaktır. Bu bağlamda, firmaların sosyal sorumluluğu reklam olanağı yahut görüntüsel bir unsur olarak değil; kendilerini var eden, kaynak sunarak onlara yaşama firsatı veren topluma karşı bir borç olarak değerlendirmelerinin sağlıklı olacağı belirtilmelidir. Bu borcun ifa edilmesinde öncelikli iş, yaşam hakkını koruyacak düzenlemelerin hayata geçirilmesidir. Yaşam hakkını ihlal eden iş organizasyonu sistemlerinin tasfiyesi, sürdürülebilirlik açısından da büyük önem taşımaktadır. Öte yandan, KSS'den adil uygulamaların yaygınlaştııılması, çevresel kaynakların korunarak sürdürülebilirliğe katkıda bulunulması ve hesap verebilirliğin geliştirilmesi konularında beklentiler olduğu da bildirilmektedir (Hirschland, 2006; Smith, 2011). Bütün bunlar için, KSS'nin işle ilgili tüm sorumlulukları kapsayan bir düzeyde ve stratejik düşünceye entegre edilmiş bir biçimde ele alınarak kurgulanması ve yapılandırılması gerekmektedir (Sanford, 2011). Iş̧ dünyasında, sosyal sorumluluğun duyarlılık gösterisi değil etkin ve yapıcı eylem olarak algılanması, içselleştirilmesi ve öğretilmesi için programlar geliştirilmelidir.

KSS'nin sadece paydaşlara değil, çevreye, gelecek nesillere ve insanlı̆a karşı sorumlulukları içerdiği de unutulmamalıdır (Robertson et al., 2016). Bu bağlamda, sosyal sorumluluğun yalnızca firmalarca üstlenilebilecek bir yükümlülük olmadığı ifade edilmelidir. ${ }^{3}$ Sorumlu ve sürdürülebilir iş uygulamalarının yaygınlaştırılmasında kamu desteği önemlidir. Özellikle iş sağlığı ve güvenliğine ilişkin çabaların gerek ulusal gerekse de işletme düzeyinde ele alınmaları önerilmektedir (ILO, 2009). Dolayısıyla, sosyal sorumluluk hususunda devletler de üstlerine düşeni yapmalıdırlar. Öncelikle de kapsamlı mutabakatlar neticesinde oluşmuş bulunan ve çoğunlukla çalışma hayatındaki kalitenin yükselmesini amaçlayan ilgili uluslararası sözleşmeleri imzalayarak, söz konusu anlaşmalarda işaret edilen ilerletici uygulamaların gerçek anlamda yürürlüğe girmelerini sağlamalıdırlar. Sosyal sorumluluk konusunda devletlerin katkıları kritik önem taşımaktadır, zira kurumsal sosyal sorumluluğun sürdürülebilirliği büyük aktörlerin desteği olmaksızın gerçekleşemeyecektir. Öte yandan, kurumsal sosyal sorumluluğun gelişmiş ve gelişmekte olan ülkelerde farkı biçimlerde ele alındığı bilinmektedir. Bu ülkelerde KSS'nin odaklandığı noktalar ve şirketlerden beklenenler de birbirinden farklıdır (Chandler and Werther, 2014; Skouloudis et al., 2016). Gelişmiş ülkelerde KSS'nin stratejiye entegre edilmesi, gelişmekte olan ülkelerde ise kalkınmanın sürdürülebilirliğini desteklemesi ön plana çıkmaktadır. Özellikle gelişmekte olan ülkelerde kamu desteğinin önemi belirginleşmektedir. Zaman zaman zorlama ve yaptırımları da içeren müdahalelerle seyredebilen -ancak tutarlı ve bütünlüklü yaklaşımdan taviz vermeyen- bir kamu desteği, gelişmekte olan ülkelerde KSS'yi sürdürülebilir kalkınmanın en önemli aracı ve toplumsal barışın anahtarı haline getirebilecektir. Dünya genelinde -bugüne kadar- KSS'ye egemen olan bakış açısı büyük ölçüde Anglo-Amerikan ve -kısmen- Asyalı bir bakış açıııdır (Farrington et al., 2017). Bununla birlikte, yeni gelişen ve hızlı büyüyen ekonomilere sahip bölgelerden doğacak çok uluslu firmaların, ileride kültürel bakımdan farklı KSS anlayışlarına kaynaklık edebilecekleri öngörülmektedir (Blowfield and Murray, 2008, p. 369). KSS'nin yapılandııılmasında, yaşam hakkının korunmasına verilecek öncelik ise -ülkelerin gelişmişlik seviyesi ve kültürel farklııkların ötesinde- küresel ölçekte ana ilke olarak değerlendirilmelidir.

KSS'nin sağlıklı bir biçimde yeniden yapılandırılmasında, yönetim düşünürleri başta olmak üzere aydınlara ve geniş olanaklara sahip kurumsal aktörlere büyük rol düşmektedir. Kurumsal sosyal sorumlulukla ilgili meseleleri kamuoyu duyarlılı̆ı̆ı havale etmek, sorunları erteleme ve çözümsüzlüğe sürükleme dışında bir anlam taşımayacaktır. Kamuoyu duyarlıı̆ı çözüme katkı sağlayabilir, ancak kamuoyu enerjisi bir noktadan sonra tükenmeye mahkûm olduğundan sorun çözülemez. KSS sorunlarının denetimlerle halledilebilecek meseleler olarak algılanmaları da problemlidir. Özellikle, denetimin büyük ölçüde cezalandırma amaçlı bir yöntem olarak kullanıldığına ilişkin algıların güçlü olduğu kültürlerde, KSS'nin sağııklı bir biçimde yapılandırılması yalnızca denetimle gerçekleştirilemez. Sistematik çerçevelere ve yüksek katılımlı bir yönelime intiyaç duyulmaktadır. Sistemli biçimde kurgulanmamış KSS çabaları, PR uygulamalarından öte anlam taşımayacaktır (Frankental, 2001). Süreli projelere değil -süreli proje ve çalışmaların katkılarını yadsımaksızın- sürekli ilişkilere dayalı bir KSS anlayışı geliştirilmelidir. KSS çabaları yapılandırılırken, geçmişteki olumsuzluklar sistematik biçimde incelenmeli, bunlardan öğrenme fırsatı olarak yararlanılması sağlanmalıdır. Sosyal sorumsuzluğun ürünleri olan çeşitli şirket skandalları ve iş faciaları bu doğrultuda değerlendirilmelidir.

\section{SONUÇ, ÖNERI VE KISITLILIKLAR}

Bu çalışma üç alanda yoğunlaşmaktadır: KSS tanım ve ilkelerinin yaşamsal ihtiyaçlarla ilişkili meydan okumalar doğrultusunda güncellenmesi, günümüzde KSS ile ilişkilendirilmesi öncelik taşıyan alanların belirlenmesi ve KSS'nin kurgulanması ve yapılandırılmasına yönelik genel önerilerin geliştirilmesi. Çalışmada KSS tanım ve ilkelerinin güncel ve yaşamsal meseleleri içerecek biçimde revize edilmeleri için önerilerde bulunulmakta; kurumsal sosyal sorumluluğun öğrenme süreçleri, mikro yönetim ve sosyal aylaklık konuları ile birlikte değerlendirilmesi gerektiği öne sürülmektedir. Söz konusu üç faktör, KSS faaliyetlerinin kurgulanması açısından öncelikli değerlendirme/kontrol faktörleri olarak ele alınabilirler. Gelecekteki araştırmalarda, KSS'nin bu çalışmada üzerinde durulmamış boyutları ile ilişkili farklı faktörler önerilebilir ve tartışılabilir. Yine gelecekteki çalışmalarda, işletmecilik dışındaki alanlarla ilişkili bilim insanları ve araştırmacıların da kurumsal sosyal sorumluluk konusunda düşünce üretmeleri, meselenin daha gerçekçi bir zeminde tartışıması ve bütünlüklü bir biçimde anlaşılması noktalarında yararlı olacaktır. Yöneticiler, iş süreçlerinin bütünlüğüne entegre edilmiş bir KSS anlayışı geliştirme doğrultusunda, bu çalışmada ve benzerlerinde öne sürülen görüşlerden yararlanabilirler. Aslında yalnızca araştırmacıların değil, yöneticilerin de doğası gereği dinamik bir alanı ifade eden KSS konusunda yeni yaklaşımlar üretmeleri oldukça önemlidir. Uygulama içerisinde geliştirilecek yeni bakış açıları şüphesiz yararlı olacak, sadece iş yaşamına değil gelecekteki araştırmalara da kılavuzluk

${ }^{3}$ Firmalarca yürütülen KSS faaliyetlerinin, hükümete ait olan bazı sorumlulukları üstlenerek, demokratik toplumda var olması gereken dengelere zarar verici bir rol oynadıklarını ileri süren eleştirel bir görüş mevcuttur (Yakabuski, 2008). 
edebilecektir. Enformasyonun rahatça gezineceği ve sosyal sorumsuzluğun yıkıcı etkilerinin bugün öngörülenin çok ötesinde olacağı geleceğin dünyası için, KSS konusundaki her katkı değer taşımaktadır.

\section{KAYNAKLAR}

Abrams, F. W. 1951. "Management's responsibilities in a complex world", Harvard Business Review, 29(3): 29-34.

Banerjee, S. B. 2007. Corporate social responsibility: the good, the bad and the ugly. Cheltenham, UK: Edward Elgar Publishing.

Baraz, B. 2011. "Kurumsal itibar ve sosyal sorumluluk", Kurumsal itibar ve paradigmalar (ed. A. N. Şakar) içinde, s. 77-100; İstanbul, Türkiye: Beta Yayınları.

Bénabou, R. \& Tirole, J. 2009. “Individual and corporate social responsibility”, Economica, 77: 1-19.

Bessant, J. \& Tidd, J. 2015. Innovation and entrepreneurship ( $3^{\text {rd }}$ edition). Hoboken, NJ, USA: John Wiley \& Sons.

Blowfield, M. \& Murray, A. 2008. Corporate social responsibility: a critical introduction. New York, NY, USA: Oxford University Press.

Bowen, H. R. 1953. Social responsibilities of the businessman. New York, NY, USA: Harper \& Row.

Brammer, S., Jackson, G. \& Matten, D. 2012. “Corporate social responsibility and institutional theory”, Socio-Economic Review, 10(1): 3-28.

Burke, E. M. 2005. Managing a company in an activist world: the leadership challenge of corporate citizenship. Westport, CT, USA: Praeger Publishers.

Carroll, A. B. 1979. “A three-dimensional conceptual model of corporate performance”, Academy of Management Review, 4(4): 497-505.

Carroll, A. B. 1991. "The pyramid of corporate social responsibility: toward the moral management of organizational stakeholders", Business Horizons, 34(4): 39-48.

Carroll, A. B. \& Shabana, K. M. 2010. "The business case for corporate social responsibility: a review of concepts, research and practice", International Journal of Management Reviews, 12(1): 85-105.

Chandler, D. \& Werther, W. B. 2014. Strategic corporate social responsibility: stakeholders, globalization, and sustainable value creation ( $3^{\text {rd }}$ edition). Thousand Oaks, CA, USA: Sage.

Compa, L. 2015. “Corporate hypocrisy: violations of trade union rights by European multinational companies in the United States", Revista Derecho Social y Empresa, 4: 15-32.

D’Amato, A., Henderson, S. \& Florence, S. 2009. Corporate social responsibility and sustainable business: a guide to leadership tasks and functions. Greensboro, NC, USA: CCL Press.

Dixon, N. M. 1992. "Organizational learning: a review of the literature with implications for HRD professionals", Human Resource Development Quarterly, 3(1): 29-49.

Ersöz, H. Y. 2007. Türkiye'de kurumsal sosyal sorumluluk anlayışının gelişiminde meslek ve sivil toplum kuruluşları. İstanbul, Türkiye: İstanbul Ticaret Odası Yayınları.

Evans, W. R., Haden, S. S. P., Clayton, R. W. \& Novicevic, M. M. 2013. "History of management thought about social responsibility", Journal of Management History, 19(1): 8-32.

Farrington, T., Curran, R., Gori, K., O’Gorman, K. D. \& Queenan, C. J. 2017. "Corporate social responsibility: reviewed, rated, revised", International Journal of Contemporary Hospitality Management, 29(1): 30-47.

Flammer, C. \& Luo, J. 2017. "Corporate social responsibility as an employee governance tool: evidence from a quasi-experiment", Strategic Management Journal, 38(2): 163-183.

Fleming, P. \& Jones, M. T. 2013. The end of corporate social responsibility: crisis and critique. London, UK: Sage.

Frankental, P. 2001. “Corporate social responsibility -a PR invention?”, Corporate Communications: An International Journal, 6(1): 18-23.

Freeman, I. \& Hasnaoui, A. 2011. "The meaning of corporate social responsibility: the vision of four nations", Journal of Business Ethics, 100(3): 419-443.

Friedman, M. 1970. "The social responsibility of business is to increase its profits", New York Times Magazine, September 13: 32-33.

Fukukawa, K., Balmer, J. M. T. \& Gray, E. R. 2007. “Mapping the interface between corporate identity, ethics and corporate social responsibility", Journal of Business Ethics, 76(1): 1-5.

Garriga, E. \& Melé, D. 2004. “Corporate social responsibility theories: mapping the territory”, Journal of Business Ethics, 53(1): 51-71.

Gil Estallo, M. d. I. Á., Giner de-la Fuente, F. \& Griful-Miquela, C. 2007. "The importance of corporate social responsibility and its limits", International Advances in Economic Research, 13(3): 379-388.

Hayek, F. A. 1967. Studies in philosophy, politics and economics. London, UK: Routledge and Kegan Paul.

Henderson, D. 2001. Misguided virtue: false notions of corporate social responsibility. London, UK: Institute of Economic Affairs.

Hino, Y. \& Zennyo, Y. 2017. “Corporate social responsibility and strategic relationships”, International Review of Economics, doi:10.1007/s12232-016-0267-y 
Hirschland, M. J. 2006. Corporate social responsibility and the shaping of global public policy. New York, NY, USA: Palgrave Macmillan.

Huber, G. P. 1991. “Organizational learning: the contributing processes and the literatures", Organization Science, 2(1): 88-115. ILO (International Labour Organization). 2009. Health and life at work: a basic human right. Geneva, Switzerland: ILO Publications. Isaksson, L., Kiessling, T. \& Harvey, M. 2014. “Corporate social responsibility: why bother?”, Organizational Dynamics, 43(1): 64-72. Kanji, G. K. \& Chopra, P. K. 2010. “Corporate social responsibility in a global economy”, Total Quality Management, 21(2): 119-143. Kağnıcıoğlu, D. 2007. Endüstri ilişkileri boyutuyla sosyal sorumluluk. Eskişehir, Türkiye: Anadolu Üniversitesi Yayınları. Klonoski, R. J. 1991. "Foundational considerations in the corporate social responsibility debate”, Business Horizons, 34(4): 9-18. Kusunoki, S. 2016. "Hayek on corporate social responsibility", Constitutional Political Economy, 27(1): 93-110.

Liden, R. C., Wayne, S. J., Jaworski, R. A. \& Bennett, N. 2004. “Social loafing: a field investigation”, Journal of Management, 30(2): 285-304. Liu, L. 2010. Conversations on leadership: wisdom from global management gurus. San Francisco, CA, USA: Jossey-Bass.

Luthans, F. \& Hodgetts, R. M. 1972. Social issues in business: poverty, civil rights, ecology and consumerism. New York, NY, USA: Macmillan.

Malan, D. 2005. "Corporate citizens, colonialists, tourists or activists? Ethical challenges facing South African corporations in Africa", Journal of Corporate Citizenship, 18: 49-60.

Mohr, L. A., Webb, D. J. \& Harris, K. E. 2001. "Do consumers expect companies to be socially responsible? The impact of corporate social responsibility on buying behavior", The Journal of Consumer Affairs, 35(1): 45-72.

Moon, J. 2014. Corporate social responsibility: a very short introduction. Oxford, UK: Oxford University Press.

Nalband, N. A. \& Al-Amri, M. S. 2013. “Corporate social responsibility: perception, practices and performance of listed companies of Saudi Arabia", Competitiveness Review: An International Business Journal, 23(3): 284-295.

Ofodile, U. E., Altschuller, S., Dolize, A. \& Fessler, M. 2012. “Corporate social responsibility”, The International Lawyer, 46(1): 181-197.

Orlitzky, M., Siegel, D. S. \& Waldman, D. A. 2011. "Strategic corporate social responsibility and environmental sustainability", Business \& Society, 50(1): 6-27.

Quelch, J. A. \& Jocz, K. E. 2009. “Can corporate social responsibility survive recession?”, Leader to Leader, 53: 37-43.

Randel, A. E. 2002. "The maintenance of an organization's socially responsible practice: a cross-level framework", Business and Society, 41(1): 61-83.

Robertson, R. W., Parmenter, C. \& Low, P. 2016. "Theory and practice of corporate social responsibility", i-manager's Journal on Management, 10(4): 1-9.

Sanford, C. 2011. The responsible business: reimagining sustainability \& success. San Francisco, CA, USA: Jossey-Bass.

Schwartz, M. S. \& Carroll, A. B. 2003. “Corporate social responsibility: a three-domain approach”, Business Ethics Quarterly, 13(4): 503530.

Shrivastava, P. 1994. "Ecocentric leadership in the $21^{\text {st }}$ century", Leadership Quarterly, 5(3/4): 223-226.

Skouloudis A., Isaac, D. \& Evaggelinos, K. 2016. "Revisiting the national corporate social responsibility index", International Journal of Sustainable Development \& World Ecology, 23(1): 61-70.

Smith, A. D. 2011. "Corporate social responsibility implementation: comparison of large not-for-profit and for-profit companies", International Journal of Accounting and Information Management, 19(3): 231-246.

TBB (Türkiye Barolar Birliği). 2014. Soma maden faciası raporu. Ankara, Türkiye: Türkiye Barolar Birliği Yayınları.

Thompson, A., Petaraf, M., Gamble, J. \& Strickland III, A. J. 2016. Crafting and executing strategy: the quest for competitive advantageconcepts and cases (20 th edition). New York, NY, USA: McGraw-Hill Education.

Turker, D. 2009. “How corporate social responsibility influences organizational commitment”, Journal of Business Ethics, 89(2): 189-204.

Wagner, T., Lutz, R. J. \& Weitz, B. A. 2009. "Corporate hypocrisy: overcoming the threat of inconsistent corporate social responsibility perceptions", Journal of Marketing, 73(6): 77-91.

Walton, C. C. 1968. Corporate social responsibilities (2 ${ }^{\text {nd }}$ edition). Belmont, CA, USA: Wadsworth.

Welford, R. 1997. Hijacking environmentalism: corporate responses to sustainable development. London, UK: Earthscan.

White, R. D. 2010. “The micromanagement disease: symptoms, diagnosis, and cure”, Public Personnel Management, 39(1): 71-76.

Wright, R. F. 1999. "Effect of micro management on job satisfaction and productivity: a case study", Vision: The Journal of Business Perspective, 3: 51-61.

Yakabuski, K. 2008. "The kindness of corporations", The Globe and Mail, June 27: 66.

Yalman, G ve Çelik, C. 2016. "Maden iş̧̧iliğinin ekonomi politiği ve Soma'da işçileşme süreci”, iki yııın ardından Soma maden faciası raporu (ed. Türk Sosyal Bilimler Derneği Çalışma Grubu) içinde, s. 10-17; Ankara, Türkiye: Türk Sosyal Bilimler Derneği. 